\title{
Global public spending efficiency in Tuscan municipalities
}

\author{
Giovanna D'Inverno ${ }^{\mathrm{a}, *}$, Laura Carosi $^{\mathrm{b}}$, Letizia Ravaglic \\ ${ }^{a}$ IMT Institute for Advanced Studies Lucca, Lucca, Italy \\ ${ }^{b}$ Department of Economics and Management, University of Pisa, Italy \\ ${ }^{c}$ IRPET - Istituto Regionale per la Programmazione Economica della Toscana, Florence, \\ Italy
}

\begin{abstract}
The paper presents a Data Envelopment Analysis aimed at studying the efficiency of Tuscan municipalities' public expenditure. Five strategic functions of Tuscan municipalities are first considered carrying out a non-aggregate analysis; then the overall expenditure composition of each municipality and the global spending efficiency are analysed by a proposed composite indicator. The main determinants affecting the municipalities' efficiency were further investigated. In particular, the obtained results may be consistently included in the longstanding debate on the municipal size, proving that the bigger the municipality, the greater its level of public expenditure efficiency.

Keywords: DEA, Efficiency, Local governments, Composite indicator, Tobit regression
\end{abstract}

2010 MSC: 90B50, 90C05

\section{Introduction}

After decades of research, the local government efficiency evaluation is still at the centre of political and academic debate, in the public sector literature, and even more, in the public administration and management literature. The

\footnotetext{
${ }^{*}$ Corresponding author

Email addresses: giovanna.dinverno@imtlucca.it (Giovanna D'Inverno), laura.carosi@unipi.it (Laura Carosi), letizia.ravagli@irpet.it (Letizia Ravagli)
} 
5 economic performance measurement and comparison at each government level remain a relevant issue in the current agenda, being a recurrent theme during the evolution of the public sector management along its three different phases [55]. The first one goes from the late 19th century through the late 1970s/early 1980s; at least in the majority of the European countries, the state was supposed to satisfy all the social and the economic needs of its citizens. Recalling a very famous sentence, this should have been done "from the cradle to the grave". "Administration", "bureaucracy" and "public service provision" characterized the activity of the public administration in that period. The second phase can be associated with the "New Public Management (NPM)" paradigm [45]. In this era, "market", "managerialism", "input and output control", "performance evaluation" got a foothold in public administration [56]; both theoretical and political debate faced the necessity of combining public service provisions with the containment of public spending. So, since the beginning of the 1990s, "efficiency", "effectiveness" and "quality service" have become the keywords of the public sector management [54]. From the late 1990s, the New Public Management paradigm has been heavily criticized and many empirical evidences underlined its failure: this has lead to new proposals which attempt to give a more modern idea of Public Management Governance (see for example [39, 55]). Even in these new contexts, performance evaluations are still considered as a 25 key tool, something essential for policy makers' decisions. The provision of a robust efficiency measurement and the implementation of an effective system of incentives are in the agenda of both politicians and academics [29].

Local governments are the most involved organizations in the evaluating process; during the last years, many key public functions have been transferred from national to local authorities and hence these latter ones have increased their importance [38, 3, 4, 50]. As it is better specified in Section 2, there is a growing number of papers dealing with the efficiency evaluations of local governments and the identification of those environmental variables which may affect the efficiency. Several different aspects of local government activity have been evaluated with different techniques. The present paper fits into this wide 
literature and in particular it aims at evaluating the efficiency of the Italian municipalities located in Tuscany.

To respect the budget constraints, the national government often makes cuts in transfers to regional and local governments and tries to reorganize public 40 services supply. Referring to Italy, this subject is very relevant due to the stringent budget constraints imposed at European level, like the Stability and Growth Pact and more recently the Fiscal Compact. Of course, this strengthens the importance and the usefulness of efficiency evaluations. In Tuscany and, in general, in the Italian context, the presence of inefficiency in the municipal expenditure is due to at least three aspects: the presence of much too small municipalities, the partial overlapping of functions carried out both by provinces and municipalities and the lack of an unitary management for densely populated metropolitan areas [46]. In this paper the first aspect is specifically investigated: small municipalities turn out to be inefficient because they are unable to exploit scale economies in the provision of public goods and services and, as a consequence, the services they can provide are poorer and limited to essential needs. So, the issue of the local governments optimal size to settle these diseconomies is still controversial and matter of debate. In particular, Tuscany has promoted institutional and administrative reforms to overcome the presence of too many fragmented municipalities and to define appropriate territorial areas for planning and supply of public services: since the 1970s, there was awareness among scholars and regional administrators that very small municipal dimensions affected public services supply and that institutional boundaries were de facto already overcome in the everyday life of families and businesses. The 68/2011 regional law represents an example of the legislator attempt to define the optimal municipal size to offer fundamental public services by promoting the joint management and/or the merger among the smallest Tuscan municipalities. In this context, the expenditure efficiency analysis of Tuscan municipalities is proposed through a Data Envelopment Analysis (DEA). This paper contributes to ${ }_{65}$ the literature by supplying new evidences concerning the efficiency analysis of local governments and by proposing an innovative use of a composite indica- 
tor. Additionally, the obtained results can help the policy-maker to identify the inefficient municipalities and to give suggestions on possible reorganizations of the local governments.

70 The remainder of this paper is organised as follows. Section 2 provides a literature review to place this research into context. Section 3 introduces the model specification, describing the 3-stage DEA based approach performed in the analysis. Section 4 presents the empirical analysis, explaining the data choice and the critical discussion of the obtained results. Finally, Section 5 concludes the 75 paper.

\section{Literature review}

Despite the measurement of the efficiency in the private sector dates from the seminal contribution of Farrell [41], the issue of the local governments efficiency has been addressed just since the 1990s. The existing literature on the municipal efficiency analysis can be divided into two-branches [38. On the one hand, there are numerous studies on individual public services, such as solid waste, sewage disposal, water, energy provision, hospitals, municipal savings banks, public libraries, road maintenance, fire protection, care for the elderly sector, local police services, public transportation and pre-school education (for an overview see Ref. [18]). On the other hand, there are studies that analyse global municipal efficiency for various countries: Belgium [30, 32, 43, Finland [51, Norway [19, Brazil 61, Spain 4, 10, 13, 28, 57, Portugal [2, 3, 4, 29], Czech Republic [64, Japan [52, 53], Germany [42, 47], Greece [8, 38] and Italy [5, 15, 17, 49, 50] (for earlier studies review see Refs. [31, 69]). This second type of studies sometimes attempts to analyse the relationship between municipal performances and some important topics, like the relevance of the municipal size, the effect of public function decentralization on the municipalities, the impact of fiscal decentralization, the influence of the effects of spatial closeness between municipalities, and other aspects. According to many authors, there is an advantage in the use of a comprehensive approach, compared to the studies 
focused on specific functions: it is the ability to take into account the opportunity cost perceived by the municipality in deciding the allocation of resources to different services, the possible synergies of expenditure and the quantification of the total savings of resources. Following this part of the efficiency literature, in this paper the global public expenditure efficiency analysis of the Tuscan municipalities is performed through DEA and, as far as the authors know, this is the first application for the Tuscan region. The choice of the Tuscan framework is undoubtedly linked to its topical feature: even the Tuscan legislator has promoted institutional and administrative reforms to overcome the presence of inefficiency in the municipalities expenditure, in particular in relation to the municipal size. For this reason, in this context a specific attention is dedicated to the municipal size effect on the expenditure efficiency, adding new evidences to the existing literature (see for example Refs. [18, 38]).

From a methodological point of view, there are alternative available methods for the efficiency analysis of production processes in both private and public sector. They differ mainly in the way the unknown and unobservable "efficiency frontier" is inferred from the data. These different techniques can be classified basically in two alternative approaches: the econometric and the optimization approach. The first one specifies a production function and normally recognizes that the deviation away from this given technology (as measured by the error term) is composed of two parts, one representing randomness (or statistical noise) and the other inefficiency. Among the various techniques belonging to the econometric approach the "stochastic frontier analysis" (SFA), introduced by Aigner et al. [7], plays a central role. Following Worthington [68, the first studies of local government cost efficiency with this approach are proposed by De Borger and Kerstens [30, Deller et al. 33] and Hayes and Chang [44]. Using this technique, a sizeable structure is imposed upon the data from a strict parametric form and distributional assumption, to determine the absolute economic efficiency of the units under analysis against some imposed benchmark [37. On

125 the contrary, the mathematical programming approach seeks to evaluate the relative efficiency of one unit compared to the others. The most commonly em- 
ployed version of the optimization approach is the linear programming model referred to as "data envelopment analysis" (DEA), introduced by Charnes et al. [21], based on the concept of efficiency proposed by Farrell [41]. DEA essentially calculates the economic efficiency of a given organisation with respect to the performance of other organisations producing the same good or service, rather than against an idealised standard of performance. Given its non-parametric basis, it is possible to considerably vary the specification of inputs and outputs and not to specify a particular form. Still following Worthington, De Borger and Kerstens [30] and Vanden Eeckhaut et al. 65] give the first contributions for the local government cost efficiency analysis with this technique. Moreover, a less-constrained alternative to DEA often employed in the analysis of the public sector economic efficiency is known as "free-disposal hull" (FDH), introduced by Deprins et al. [34] and applied to local governments for the first time by De Borger and Kerstens 30 and by De Borger et al. 32. The methodological literature to date provides inconclusive evidence concerning the sensitivity of local government efficiency rankings to these alternative technologies. It should be emphasised that the SFA and DEA approaches address different questions, serve different purposes and have different informational requirements [37]: for these reasons, DEA and SFA should be considered as complementary methods in the local public sector efficiency analysis. Recently, Da Cruz and Marques [29] carried out a very detailed and systematic literature review of the papers published in peer-reviewed and top-ranked journals dealing with the global performance of local governments: DEA, FDH or SFA methodologies are mostly used and the data choice is strictly affected by the local governments range. In particular, as regards the data choice, the efficiency analysis at the global level covers several areas of municipal activity: many inputs and outputs related to different municipal areas have to be considered. To globally encompass all the municipal functions in a single indicator, several ways have been proposed in the recent literature. Some authors conceive a multi input-output DEA model (see Refs. [32, 68, 9]), while some others aggregate the different functions by constructing a composite indicator. Regarding this latter approach, it is worth 
citing the contribution of Afonso and Fernandes 3 . The authors use a Total Municipal Output Indicator (TMOI) to put together different outputs (a similar approach can be found for example in Ref. [1]). They assume that the TMOI depends on several economic and social variables, belonging to different policy areas. For each policy area a total municipal sub-indicator (TMSOI) must be previously computed: this indicator is calculated by centring each variable around the mean of all observations and then using an unweighted average of all variables for policy area. Then, the TMOI is computed as the sum of all the subindicators. The DEA analysis is then performed using as output of the model either the composite TMOI or alternatively the several sub-indicators. Another way of constructing composite indicators is based on the so-called "Benefit of the doubt" approach (see Cherchye et al. [22]). In this case, separate subindicators are first computed for different objects and then they are aggregated in a composite indicator by means of their weighted sum. The weights are chosen so to maximize the value of the composite indicator: in other words, they are the most favourable weights for the evaluated unit. However, in constructing the overall efficiency score, a common system of weights would be preferable; in this light, Despotis [35] suggests a procedure which remains in "the spirit" of DEA and which determines the same weights for every unit. This kind of composite indicator is often defined as DEA-like composite indicator and it is used in several different contexts, such as the assessment of the human development index and the evaluation of the quality of life and of the well being (see for example [14] and [36]). As far as the authors know, it has not yet been applied to the local government expenditure efficiency analysis: this paper contributes to the literature by introducing the use of this DEA-like composite indicator for the computation of the global efficiency scores. Moreover, to validate the provided results and to give an interpretation of the global efficiency scores in 185 terms of municipal expenditure composition, also a further composite indicator is proposed. 


\section{Model specification}

To evaluate the overall spending efficiency, a 3-stage DEA based approach is performed: first of all, the individual efficiencies associated with five major municipal functions are computed; then the municipal global efficiency index is generated considering a common set of weights; finally, statistical analysis are used to assess the effect of some contextual variables on the global efficiency indicator. In the following, each stage is explained in more details.

\subsection{Stage 1: DEA for each individual municipal function}

As it has been already underlined in Section 2, DEA is a non-parametric technique which is particularly suitable in evaluating the efficiency of the public sector. It does not require any specific functional form of the production frontier and gives intuitive ideas to correct the found inefficiency. Through a linear programming approach, DEA constructs the efficient frontier; first of all for each unit to be evaluated, the so-called Decision Making Unit (DMU), the set of inputs and output are detected. Then DEA models analyse whether either a given output quantity is produced with minimum input (input-oriented DEA model) or the maximum output is produced with a given input quantity (output-oriented DEA model). The efficiency score varies from 0 and 1 and it is determined by the ratio between the weighted sum of outputs and the weighted sum of inputs. Moreover, regarding the possibility of allowing variable returns to scale or not, two different specifications can be distinguished: the constant returns to scale DEA model (CRS) and the variable returns to scale DEA model (VRS), introduced respectively by Charnes et al. 21] and Banker et al. [12].

In the present analysis, Tuscan municipalities are the evaluated DMUs. As a first step, to perform a global efficiency analysis, five DEA models are run to separately assess the efficiency of the following municipal functions: "General administration" (GA), "Social Services" (SS), "Educational services" (ES), "Road maintenance and local mobility" (RM) and "Local police" (LP). Those functions have a strategic role in the local government policy and occupy a 
prominent position in the municipal budget. The peculiarities of municipal activities suggest to use the input-oriented DEA model with variable returns to scale (VRS). For the GA function, as well as the SS and the ES functions, a "one input-one output" model is used, while in the case of RM and LP functions 220 a "one input-two output" model is chosen (for further specification, see Section 4.1]. The obtained basic efficiency scores are then aggregated to analyse the overall spending performance, as explained in the next stage.

\subsection{Stage 2: Aggregating for the overall efficiency analysis}

Regarding the overall efficiency, several preliminary considerations should

be done. The global municipal spending efficiency could be evaluated by considering a DEA model with all the input and output variables detected for the non-aggregate analysis. Nevertheless, this straightforward and easy choice does not result so appealing. As DEA allows flexibility in the choice of weights on the inputs and outputs, the greater the number of included factors the lower the level of discrimination between efficient and inefficient units: so, discrimination can be increased by being parsimonious in the number of the variables. In other words, by increasing the number of inputs and/or outputs, there is automatically, by construction, an increase of the efficient DMUs. This reasoning becomes very evident looking at the DEA results stemming from the municipal analysis: gradually adding a function, in the VRS model, the number of efficient municipalities increases more and more, out of a sample of 282 units under analysis. In fact, just considering the "General administration" function there are only 5 efficient municipalities. Considering also the function for "Educational services" the number of efficient municipalities increases at 20. Then, adding the function for "Social Services" 49 municipalities result to be efficient. Finally, the number of efficient municipalities becomes very big introducing the "Road maintenance and local mobility" function, i.e. 82 efficient municipalities, and then the "Local police" function, i.e. 107 efficient municipalities: obviously, having so many efficient municipalities is not very informative and it's quite unreasonable. In the literature, there is an open theoretical debate on this is- 
sue. From one hand, different suggested "rules of thumb" are proposed in order to achieve reasonable level of discrimination; for example, there are proposed rules in [20] and in [40]. On the other hand, the definition of a stringent rule seems to be too rigid and useless in relation to the research needs (see, e.g., [24, 25]). Referring to this issue, alternative approaches have been proposed in the municipal expenditure efficiency analysis (see Section 2).

The solution adopted in the present analysis consists in the introduction of a new composite indicator which aggregates the efficiency scores of the single functions and more specifically by means of a weighted average of the basic efficiency scores. The weights are determined focusing on two main objectives: first of all, they have to generate a DEA-like index, so not to penalize the units under analysis; then, they have to avoid arbitrary choice, giving a common base for municipality comparison. To reach these goals, the "benefit of the doubt" approach (see [14, 22]) represents a necessary intermediate step to generate the municipal global efficiency index with a common set of weights. More precisely, for every municipality $j_{0}$ a preliminary composite indicator is constructed, solving the following maximization problem:

$$
\left\{\begin{array}{l}
C I_{j_{0}}=\max _{w_{j_{0}}} \sum_{i=1}^{k} y_{i j_{0}} w_{i j_{0}} \\
\sum_{i=1}^{k} y_{i j} w_{i j_{0}} \leq 1 \quad j=1, \ldots, m \\
w_{i j_{0}} \geq \epsilon \quad i=1, \ldots, k .
\end{array}\right.
$$

where $m$ is the number of evaluated municipalities, $k$ is the number of the considered functions, $y_{i j}$ represents the DEA efficiency score related to the $i_{t h}$ function of the $j_{t h}$ municipality and $w_{j_{0}}=\left(w_{i j_{0}}\right)_{i=1}^{k}$ is the weight associated with the municipality $j_{0}$. The overall efficiency score is obtained by taking a weighted sum of the five non-aggregate efficiency scores and, according to Problem 11. it corresponds to the optimal value; the optimal weights are the most favourable for the evaluated municipality $j_{0}$. Moreover Problem 1 can be seen as a standard DEA model where there is a dummy input and the nonaggregate efficiency scores are seen as output variables. As it is observed in 
14], the aforementioned Composite Indicator provides a different set of weights for each DMU and this prevents DMU's comparison on a common base. In this light, Despotis [35] states that a common set of weights can be determined by solving a suitable vector optimization problem and the corresponding solutions are found by solving the following minimization problem:

$$
\begin{cases}\min _{w_{i}, d_{j}, z} t \frac{1}{m} \sum_{j=1}^{m} d_{j}+(1-t) z \\ \sum_{i=1}^{k} y_{i j} w_{i}+d_{j}=C I_{j} \quad j=1, \ldots, m \\ d_{j}-z \leq 0 \quad j=1, \ldots, m \\ d_{j} \geq 0 & j=1, \ldots, m \\ w_{i} \geq \epsilon & i=1, \ldots, k \\ z \geq 0 & \end{cases}
$$

where $w_{i}$ represents the weight assigned to the $i_{t h}$ function and $d_{j}$ "measures" the distance between the "collective" score and the most favourable score for the $j_{t h}$ municipality, namely $C I_{j}$ which is obtained by solving Problem 1 . By construction, $d_{j}$ is non-negative for every DMU and $z$ represents the maximum of $d_{j}$; therefore $z$ is the distance between the "collective" score and the DEAlike composite indicator of the most penalized DMU (see also [14]). As $t$ varies from 0 to 1 , different sets of common weights are determined and each of them has different meaning. In the present analysis, $t=0$ is considered as the most suitable choice; actually when $t=0$, Problem 2 gives the set of common weights which minimizes $z$, that is, which maximizes the efficiency score of the most penalized DMU. The set of common weights is then used to compute the new composite indicators attesting the municipalities' global spending efficiency.

In the local administrators' opinion, the overall efficiency of a municipality has to be evaluated even through the analysis of the expenditure composition arising from its municipal balance sheet. In this light, the obtained composite indicators are compared with a second kind of global efficiency scores. Even in this latter case, the composite indicator is the weighted sum of the single 
functions' efficiency scores, but each function enters in the composite indicatotal expenditure. This other indicator takes into account the local administrators' perception and it is also helpful in validating the first DEA-like indicator. Moreover, to construct a composite indicator with a common system of weights among all the municipalities, the single function efficiency scores are weighted according to the Tuscan mean expenditure composition. For each municipality, the comparison of the two "expenditure composition" indicators may provide suggestions to enhance efficiency.

\subsection{Stage 3: Investigating municipal expenditure efficiency explanatory vari-} ables

Finally, an interpretation of the obtained indicators is provided by clustering the Tuscan municipalities according to the following main municipal features and consistently with the Tuscan hallmarks: the size, the geography, the tourism degree and the socio-economic structure through the local labour system classification. This analysis aims at investigating how specific municipal features affect the local public expenditure management and its efficiency.

With the same purpose, a Tobit regression model is also estimated; the global efficiency scores are explained taking into account the municipal characteristics and the related economic, social and political context. As suggested in the recent literature (see e.g. [6, 29], [50]), to properly conduct the third stage analysis, bias-corrected efficiency scores are computed using a bootstrap procedure (see 62, 63] ) and then used as dependent variable in the regression model.

\section{Empirical application}

\subsection{Data, inputs and outputs}

A fundamental step in the definition of the municipal efficiency analysis regards the choice of the decision variables, both for the computation of the efficiency scores (inputs and outputs) and for the explanation of its determinants. 
The Italian institutional framework strongly influences the data choice, regarding both the municipal expenditure areas and their related inputs/outputs. Specifically, "General administration", "Social Services", "Educational services", "Road maintenance and local mobility" and "Local police" are considered, as they represent not only the most fundamental competencies for the municipal budget (about the $73 \%$ of the total current expenditure in 2011, reference year of the analysis), but also for the services provided to the citizens, detailed in the following according to the municipal balance sheet expenditure items 1

- General administration: it provides services regarding the institutional bodies, the administrative office, the management of tax revenue, the technical office, military services, civil registration and electoral services, vital records and statistics.

- Educational services: it provides services regarding the nursery schools, the primary and secondary education, the school assistance, school transport and school meals.

- Social services: it provides services regarding childcare, kindergarten, services to minors, leisure structures, facilities and care for the most vulnerable population groups such as elderly and immigrants.

- Road maintenance and local mobility: it provides services regarding viability, traffic circulation, public lighting and public transport.

- Local police: it provides services regarding the municipal police, the com-

\footnotetext{
${ }^{1}$ Among the excluded municipal functions, a remark has to be made about the "Environmental management" function. It presents very heterogeneous expenditure items (e.g. the urban services, the environmental conservation services, the waste disposal service), that heavily differ among municipalities according to their own characteristics. Another source of heterogeneity comes from the presence of two different taxation systems for the environmental services, namely the TARSU ("Tassa Rifiuti Solidi Urbani") system and the TIA ("Tariffa Igiene Ambientale") system. Since DEA requires homogeneous units to be compared, the authors have preferred excluding this function from the current analysis.
} 
mercial police and the administrative police.

In the empirical literature there is a general consensus regarding the choice

320 current expenditure of each municipal area is used as input indicator, taken in non-aggregate way and expressed in absolute value. Data come from the available municipal balance sheets, published by the Home office Ministry (Ministero degli Interni) and refer to 2011.

325 ficult to find data that directly measure municipal production results: so, just surrogate measures of municipal demand are considered for performance indicators, often used as proxies for the relative services provided to the citizens. In addition, there is no information about qualitative results of the municipal over, the data available for some performance indicators sometimes have missing data with respect to some municipalities and certainly they become useless in the analysis. Taking into account these difficulties, the outputs proposed in the literature have been considered and function by function the variables have been tive tasks, as in 19, 15, 29, 30, 42, 50, 47, 52, 61. For the education services, the school age population (3-13 years old) has been taken as the catchment area of the services supplied by municipality (e.g., [19, 15, 32, 30, 43, 42, 47]). Regarding social services, the output is given by the number of municipal citizens from of the over 65 (for elderly provision) plus the number of immigrants (immigration needs), as in [2, 15, 19, 30, 42, 47, 52. Local police activities as well as the road maintenance and local mobility function are measured by the total amount of kilometres of roads to be supervised/maintained and by the amount of resident population plus the average annual tourist presence since they are considered as proxy of the potential users of these services (e.g., [4, 15, 29, 43]). In compliance with part of the existing literature, even the size of the municipal 
area could have been chosen as output at least for the administrative services, for the local police function and for the road maintenance one. Despite this, the geographical and socio-economic characteristics of Tuscan municipalities make this choice inappropriate. A preliminary statistical analysis has shown a strong bias in the outcomes due to the high heterogeneity related to this variable. However, given the importance of this aspect, the size of the municipal area is taken into account in the econometric analysis by means of the variable "density". and Transport Regional Observatory and Tuscany Region survey. They all refer to 2011, consistently with the expenditure side, and they cover 282 Tuscan municipalities. Despite Tuscany has 287 municipalities, data were not available for two of them and three municipalities have been detected as outliers. In fact, from a first analysis on municipalities' features, Firenze has been considered absolutely out of scale in comparison with all the other municipalities. This intuition has been confirmed by a super-efficiency DEA analysis which has been performed to detect outliers (see for all [1]). Actually, a super-efficiency DEA model has been run function by function: two more municipalities have been detected as outliers and therefore dropped from the current analysis.

Table 1 presents the dataset descriptive statistics for the relevant input and output variables. 
Table 1: Descriptive statistics for DEA dataset.

\begin{tabular}{|lllllc|}
\hline INPUT & N & Mean & Stdev & Min & Max \\
\hline General administration $\left(10^{3} €\right)$ & 282 & 2843.708 & 4788.804 & 143.12 & 41457.83 \\
Local police $\left(10^{3} €\right)$ & 282 & 566.7216 & 1211.233 & 2.717 & 10696.06 \\
Educational services $\left(10^{3} €\right)$ & 282 & 1177.73 & 2146.233 & 41.306 & 18580.92 \\
Road maintenance and local mobility $\left(10^{3} €\right)$ & 282 & 857.3745 & 1937.075 & 15.823 & 18751.71 \\
Social services $\left(10^{3} €\right)$ & 282 & 1653.309 & 3730.047 & 5.042 & 35413.89 \\
& & & & & \\
\hline OUTPUT & N & Mean & Stdev & Min & Max \\
\hline Total population & 282 & 11650.6 & 20235.62 & 394 & 184885 \\
Length of roads $($ Km $)$ & 282 & 139280.9 & 157103.9 & 0 & 1353082 \\
Population + Tourist presence & 282 & 11998.32 & 20536.98 & 493.4521 & 186104 \\
Population $3-13$ & 282 & 1107.486 & 1954.895 & 20 & 19640 \\
Population $0-5+$ Over $65+$ Immigrants & 282 & 4348.447 & 7763.503 & 142 & 77943 \\
\hline
\end{tabular}

\subsection{Results}

In this section, the DEA efficiency scores referred to 282 Tuscan municipalities are presented; they are computed by Coelli's software "DEAP Version 2.1: A Data Envelopment Analysis (Computer Program)" [23]. The assessment of the expenditure performance is expressed in terms of DEA scores by values between 0 and 1: the municipalities with a score equal to one are those that are fully efficient.

As explained in the previous section, for each fundamental municipal function a VRS analysis is done and for the global analysis the DEA-like composite indicator is computed. Table 2 presents in a synthetic way the main descriptive statistics of the results both for each municipal area and for the overall level: the full list of the results are available upon the request from the authors. 
Table 2: Descriptive statistics of the efficiency scores at local and global level.

\begin{tabular}{lccccccccc}
\hline & \multirow{2}{*}{ Mean } & Stdev & Min & Max & \multicolumn{5}{c}{ Percentiles } \\
& & & & & $10^{\circ}$ & $25^{\circ}$ & $50^{\circ}$ & $75^{\circ}$ & $90^{\circ}$ \\
\hline General administration & 0.59 & 0.19 & 0.15 & 1.00 & 0.37 & 0.46 & 0.58 & 0.73 & 0.84 \\
Local police & 0.43 & 0.23 & 0.02 & 1.00 & 0.14 & 0.26 & 0.42 & 0.56 & 0.76 \\
Educational services & 0.43 & 0.16 & 0.13 & 1.00 & 0.26 & 0.32 & 0.40 & 0.51 & 0.61 \\
Road maintenance & 0.35 & 0.20 & 0.03 & 1.00 & 0.14 & 0.20 & 0.30 & 0.43 & 0.61 \\
Social services & 0.45 & 0.24 & 0.02 & 1.00 & 0.18 & 0.27 & 0.40 & 0.57 & 0.83 \\
& & & & & & & & & \\
DEA-like Overall & 0.44 & 0.13 & 0.15 & 1.00 & 0.27 & 0.35 & 0.44 & 0.52 & 0.61 \\
\hline
\end{tabular}

A question may naturally arise: do specific municipal features affect the local public expenditure management and its efficiency? To address this question, four main municipal characteristics are considered in line with the Tuscan hallmarks: the size, the geography, the tourism degree and the socio-economic structure through the local labour system classification. Since from a qualitative point of view the outcomes are the same both at non-aggregate and at overall level, for the sake of brevity only the descriptive statistics for the composite indicator are reported below in Table 3 , even if it should be taken in mind that the efficient municipalities considered as peer for all the other inefficient ones vary according to each function, both in terms of number of efficient units and in terms of municipal typology. In the following, the four listed aspects are shortly analysed.

To explore the effect of the municipal size, the efficiency scores are clustered in eight different classes: as the municipal population size increases, the average of the efficiency scores among each class increases. As regards the biggest class, there is the highest minimum value of efficiency score and the highest maximum value, equal to one, meaning that according to this analysis the most and fully efficient municipality belongs to this class and it is the provincial capital Prato. Broadly speaking, all the provincial capitals result to be the most effi- 
cient municipalities: this can be seen graphically from Figure $1^{2}$. Moreover, the geographical distribution of the municipal population size reflects a similar distribution in terms of the expenditure efficiency scores: the darker the area, the more populated and efficient the municipality. This evidence makes stronger the reasoning about the municipal size: the bigger is the municipal catchment area, the lower the average cost in the provision of municipal services, which in turn makes possible to provide more differentiated and complex services. In particular, as regards the small municipalities, the inefficiency source can be related to the presence of too many small fragmented municipalities: this might suggest an aggregation among the smallest municipalities to exploit scale economies, in line with the legislative measures proposed by the Tuscany region to overcome this problematic aspect.

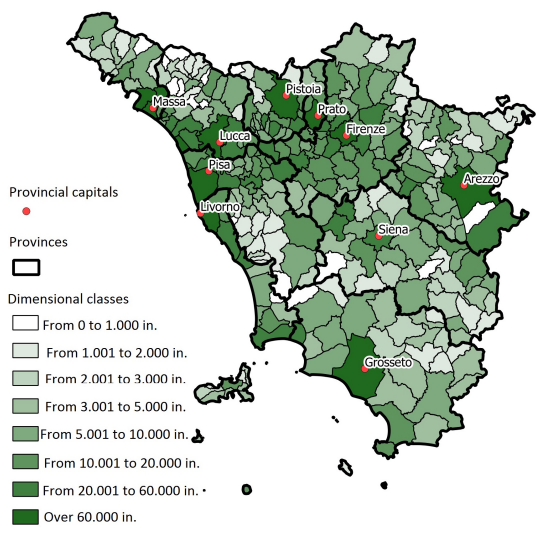

(a) By dimensional classes

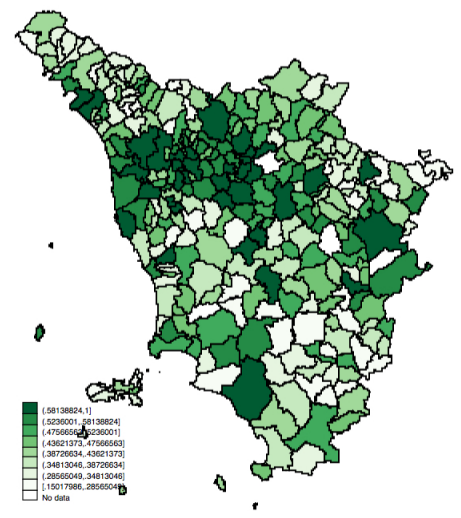

(b) By global efficiency scores

Figure 1: Geographical distribution comparison.

To check whether the municipal geography plays a role in the resources management, the "mountain" feature is considered. In line with the Italian legislation (Law 991/52, Law 657/57 and Law 142/90), the "mountain classification" distinguishes three categories: totally mountain, partially mountain

\footnotetext{
${ }^{2}$ Figure 1(b) is obtained by "Stata" program.
} 
and non-mountain. The lowest efficiency scores are present in the mountain municipalities: certainly, the difficult terrain and the smallest presence of the resident population make more inefficient the provision of the services.

As the tourism aspect is a very important Tuscan feature, the degree of municipal tourism involvement is obtained dividing into quartiles the ordered per capita tourist presence. The highest level of inefficiency is present in the municipalities with high level of tourism, while the opposite holds for those municipalities with very low level of tourism. In general, it's possible to observe that considering an increasing level of tourism, the average level of efficiency systematically decreases. Certainly, a remark must be made when considering the tourist presence: vacation property owners are not taken into account, even though they might represent a non-negligible part of the catchment area of the municipal services and so lower the inefficiency scores. Anyhow, especially the tourist municipalities subject to strong seasonality face higher costs than others (e.g. this is the case of the sea places).

Finally, the local labour systems are used to investigate the Tuscan municipalities socio-economic structure: they are territorial units of daily activities of the population that lives and works there and consist of several adjacent municipalities, geographically and statistically comparable with each other. The classification is based on the ISTAT (Italian National Institute of Statistics) 435 elaboration. The lowest average efficiency level is present in the systems without specialization, while the opposite holds for the urban systems and the manufacturing systems in the textile, leather and clothing. In relation to this last mentioned class, it's worth noting that the obtained most efficient municipality, Prato, belongs precisely to it. 
Table 3: Descriptive statistics of global efficiency scores.

\begin{tabular}{|c|c|c|c|c|}
\hline & Mean & Stdev & Min & Max \\
\hline \multicolumn{5}{|l|}{ Size class } \\
\hline From 0 to 1.000 inhab. & 0.37 & 0.12 & 0.16 & 0.58 \\
\hline From 1.001 to 2.000 inhab. & 0.32 & 0.09 & 0.20 & 0.62 \\
\hline From 2.001 to 3.000 inhab. & 0.36 & 0.06 & 0.19 & 0.51 \\
\hline From 3.001 to 5.000 inhab. & 0.39 & 0.08 & 0.22 & 0.57 \\
\hline From 5.001 to 10.000 inhab. & 0.45 & 0.10 & 0.15 & 0.71 \\
\hline From 10.001 to 20.000 inhab. & 0.54 & 0.09 & 0.37 & 0.75 \\
\hline From 20.001 to 60.000 inhab. & 0.55 & 0.12 & 0.35 & 0.82 \\
\hline Over 60.000 inhab. & 0.71 & 0.16 & 0.44 & 1.00 \\
\hline \multicolumn{5}{|l|}{ Mountain class } \\
\hline Non-mountain & 0.49 & 0.13 & 0.15 & 1.00 \\
\hline Partially mountain & 0.49 & 0.14 & 0.22 & 0.92 \\
\hline Totally mountain & 0.37 & 0.10 & 0.16 & 0.61 \\
\hline \multicolumn{5}{|l|}{ Tourism class } \\
\hline Very low tourism & 0.48 & 0.14 & 0.20 & 0.82 \\
\hline Low tourism & 0.47 & 0.15 & 0.23 & 1.00 \\
\hline Medium tourism & 0.45 & 0.12 & 0.22 & 0.80 \\
\hline High tourism & 0.38 & 0.11 & 0.15 & 0.62 \\
\hline \multicolumn{5}{|l|}{ Local labour system class } \\
\hline Without specialization & 0.37 & 0.08 & 0.24 & 0.57 \\
\hline Urban systems & 0.49 & 0.13 & 0.21 & 0.80 \\
\hline Tourism and agricultural vocation & 0.39 & 0.14 & 0.19 & 0.82 \\
\hline Manufacturing in the textile, leather and clothing & 0.49 & 0.14 & 0.20 & 1.00 \\
\hline Other manufacturing made in Italy & 0.45 & 0.14 & 0.16 & 0.92 \\
\hline Heavy manufacturing & 0.41 & 0.11 & 0.15 & 0.66 \\
\hline
\end{tabular}

\subsection{A different way of aggregation}

As pointed out before, there are several ways to aggregate the fundamental function efficiency scores into a composite indicator, according to the different assigned system of weights. Therefore, at this point of the analysis, a different composite indicator is proposed: it is computed as the weighted average of the 

trend.

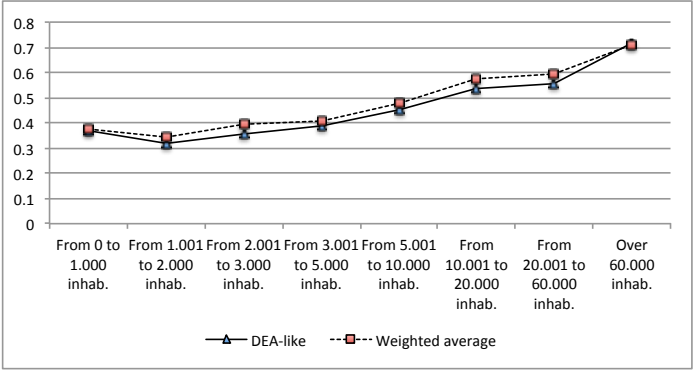

(a) By dimensional classes.

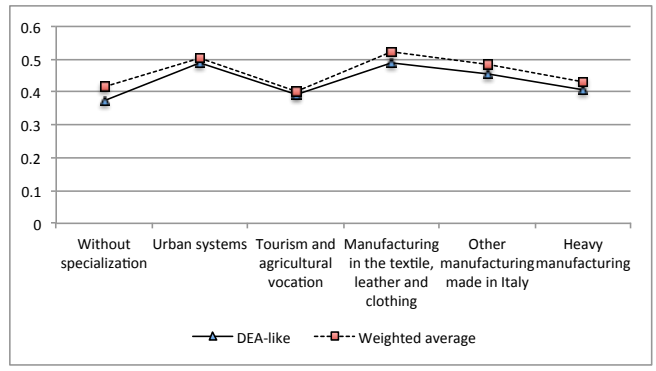

(c) By local labour system classes.

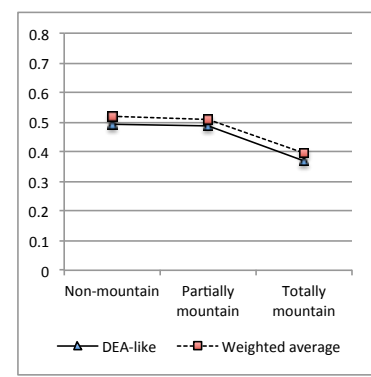

(b) By mountain classes.

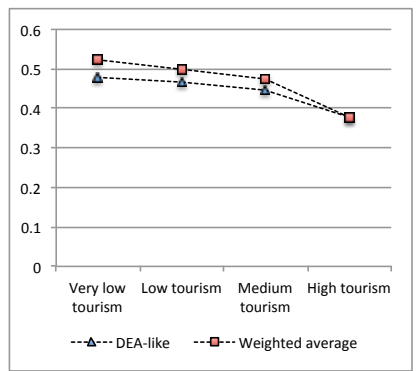

(d) By tourism classes.

Figure 2: Comparison between composite indicators scores.

Furthermore, though from a technical point of view the proposal of this kind of indicator might be simpler, from a normative point of view it might give more intuitive and then useful suggestions for the legislator and for the local governments to find room of improvements in the resource management. To reach this goal, both the composite indicator obtained by using each municipal expenditure composition and the one obtained by considering the Tuscan mean 
expenditure composition are necessary: the descriptive statistics are listed in Table 4 Using this approach, from the one hand, it becomes possible to make some considerations about the effect of the municipal expenditure allocation among the different functions on the average inefficiency. From the other hand, the units under analysis can be divided into groups according to different level of efficiency, the most frequent municipal features can be identified and compared with the commented evidences of the previous section.

\begin{tabular}{lcccccccccc} 
Table 4: & \multicolumn{1}{c}{ Descriptive statistics of the scores for municipal and Tuscan average weights. } \\
& \multirow{2}{*}{ Mean } & Stdev & \multirow{2}{*}{ Min } & Max & \multicolumn{5}{c}{ Percentiles } \\
& & & & & $10^{\circ}$ & $25^{\circ}$ & $50^{\circ}$ & $75^{\circ}$ & $90^{\circ}$ \\
\hline Municipal weights & 0.47 & 0.14 & 0.13 & 1.00 & 0.30 & 0.37 & 0.46 & 0.57 & 0.64 \\
Tuscan weights & 0.49 & 0.14 & 0.16 & 1.00 & 0.33 & 0.39 & 0.47 & 0.59 & 0.66 \\
\hline
\end{tabular}

The proposed procedure is the following. First of all, the municipalities have to be divided according to two features. The first regards the relative level of efficiency: it is the difference between each municipal composite indicator (computed considering the own municipal expenditure composition) and the median of all these computed indicators, so to have the relative efficiency of each municipality (to be noticed that the median quite coincides to the mean). The second feature regards the expenditure composition: it is the difference between each municipal composite indicator computed considering the municipal expenditure composition and the one obtained taking the Tuscan average expenditure composition. If this difference is positive, this suggests that the municipality has chosen a composition that allows it to achieve a better level of average efficiency rather than in any other resources allocation; if the difference is negative, then the municipality has chosen a composition that brings it to achieve a worse level of efficiency.

Then, Figure 3 shows the combination of these two dimensions in a graphical and intuitive way to distinguish four groups of municipalities: on the vertical axis there is the relative efficiency, while on the horizontal axis the expenditure composition aspect is considered. Municipalities are laid out into four quadrants 
according to the following way: for y positive values the municipalities belong to the Efficient quadrants, that is they result more efficient than the median, while for $\mathrm{x}$ positive values the municipalities belong to the Better quadrants, that is they have an expenditure composition that allows them to achieve a better level of average efficiency; the opposite reasoning holds respectively for the Inefficient and the Worse quadrants.

As evident, it can be said that the municipalities in the Efficient-Worse and

Inefficient-Worse quadrant have possible room of improvement in the efficiency level just changing a little the composition of the expenditure. Certainly, this suggestion should be handle carefully, especially for two reasons: the change in the expenditure brings to a change in the DEA model input, so to modify endogenously the level of the efficiency; secondly, especially for the smallest municipalities there are some binding thresholds of expenditure that cannot be avoided. Furthermore, the municipalities in the Inefficient-Worse and InefficientBetter quadrant certainly could improve their level of efficiency at least solving the present mismanagement problems and their causes. So, in conclusion, the Efficient- Better quadrant seems to collect the municipalities that behave better, according to this analysis. 


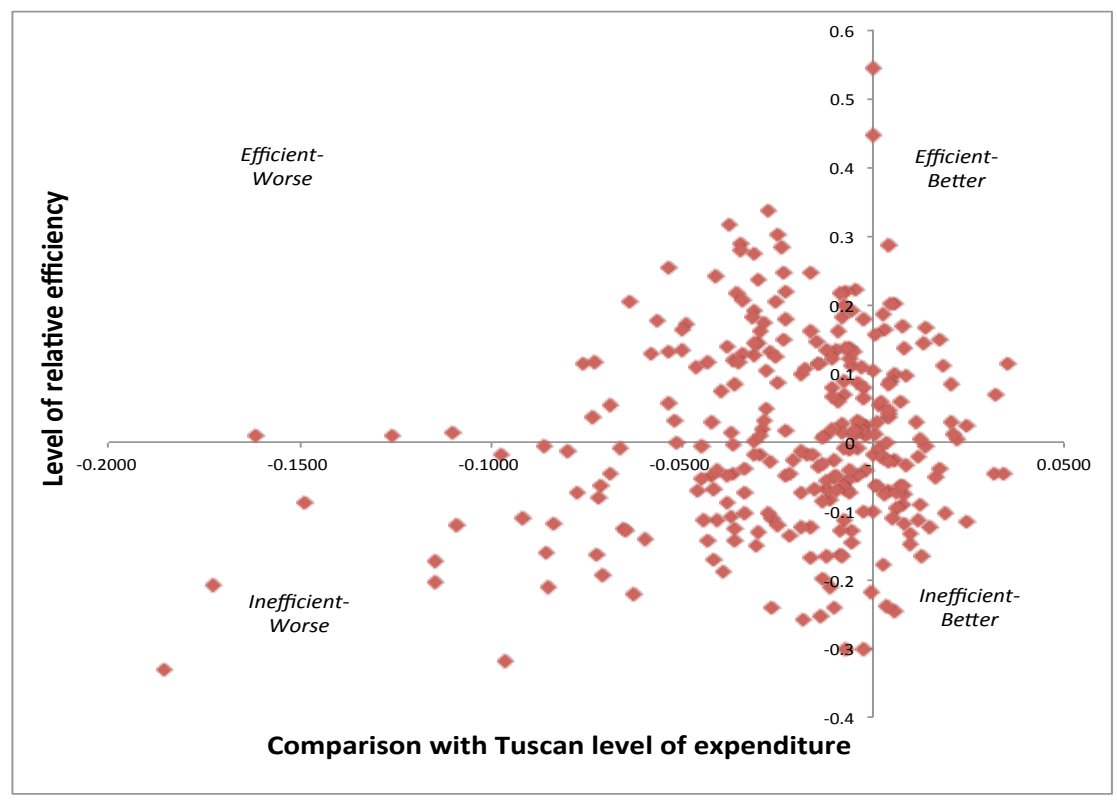

Figure 3: Municipalities by relative efficiency and expenditure composition.

In a synthetic way, Table 5 shows the main features of each quadrant according to the already used dimensional, mountain, tourism and local labour system classes and referring the number of present municipalities (in the table shortly DMUs). The dimensional class which reveals the highest percentage of the best performing municipalities (Efficient-Better quadrant) is the one with over sixty thousands of inhabitants. Referring to the other classifications, the highest percentage of the best performing municipalities lies in the non-mountain class, in the low-tourism one and in the manufacturing systems in the textile, leather and clothing one. As evident, these features recall those already presented in the previous results and again confirmed. Similar way of reasoning can be given for the other quadrants of the table. 
Table 5: Descriptive statistics of each quadrant.

\begin{tabular}{|c|c|c|c|c|c|c|c|c|c|}
\hline \multirow[b]{2}{*}{ Dimensional class } & \multicolumn{2}{|c|}{$\begin{array}{c}\text { Efficient-Better } \\
\text { quadrant }\end{array}$} & \multicolumn{2}{|c|}{$\begin{array}{c}\text { Efficient-Worse } \\
\text { quadrant }\end{array}$} & \multicolumn{2}{|c|}{$\begin{array}{c}\text { Inefficient-Better } \\
\text { quadrant }\end{array}$} & \multicolumn{2}{|c|}{$\begin{array}{l}\text { Inefficient-Worse } \\
\text { quadrant }\end{array}$} & \multirow[b]{2}{*}{ TOTAL } \\
\hline & DMUs & $\%$ & DMUs & $\%$ & DMUs & $\%$ & DMUs & $\%$ & \\
\hline From 0 to 1.000 inhab. & 3 & $18 \%$ & 2 & $12 \%$ & 1 & $6 \%$ & 11 & $\underline{65 \%}$ & 17 \\
\hline From 1.001 to 2.000 inhab. & 1 & $3 \%$ & 3 & $8 \%$ & 12 & $\underline{30 \%}$ & 24 & $60 \%$ & 40 \\
\hline From 2.001 to 3.000 inhab. & 3 & $11 \%$ & 3 & $11 \%$ & 8 & $29 \%$ & 14 & $50 \%$ & 28 \\
\hline From 3.001 to 5.000 inhab. & 6 & $13 \%$ & 9 & $19 \%$ & 7 & $15 \%$ & 26 & $54 \%$ & 48 \\
\hline From 5.001 to 10.000 inhab. & 8 & $13 \%$ & 29 & $46 \%$ & 6 & $10 \%$ & 20 & $32 \%$ & 63 \\
\hline From 10.001 to 20.000 inhab. & 9 & $18 \%$ & 34 & $69 \%$ & 3 & $6 \%$ & 3 & $6 \%$ & 49 \\
\hline From 20.001 to 60.000 inhab. & 4 & $15 \%$ & 18 & $67 \%$ & 1 & $4 \%$ & 4 & $15 \%$ & 27 \\
\hline Over 60.000 inhab. & 2 & $\underline{20 \%}$ & 7 & $\underline{70 \%}$ & 0 & $0 \%$ & 1 & $10 \%$ & 10 \\
\hline TOTAL & 36 & $13 \%$ & 105 & $37 \%$ & 38 & $13 \%$ & 103 & $37 \%$ & 282 \\
\hline Mountain class & DMUs & $\%$ & DMUs & $\%$ & DMUs & $\%$ & DMUs & $\%$ & TOTAL \\
\hline Non-mountain & 21 & $\underline{16 \%}$ & 61 & $48 \%$ & 17 & $13 \%$ & 29 & $23 \%$ & 128 \\
\hline Partially mountain & 5 & $12 \%$ & 23 & $\underline{55 \%}$ & 2 & $5 \%$ & 12 & $29 \%$ & 42 \\
\hline Totally mountain & 10 & $9 \%$ & 21 & $19 \%$ & 19 & $\underline{17 \%}$ & 62 & $\underline{55 \%}$ & 112 \\
\hline TOTAL & 36 & $13 \%$ & 105 & $37 \%$ & 38 & $13 \%$ & 103 & $37 \%$ & 282 \\
\hline Tourism class & DMUs & $\%$ & DMUs & $\%$ & DMUs & $\%$ & DMUs & $\%$ & TOTAL \\
\hline Very low tourism & 15 & $\underline{21 \%}$ & 33 & $\underline{47 \%}$ & 3 & $4 \%$ & 19 & $27 \%$ & 70 \\
\hline Low tourism & 8 & $11 \%$ & 31 & $44 \%$ & 11 & $15 \%$ & 21 & $30 \%$ & 71 \\
\hline Medium tourism & 7 & $10 \%$ & 30 & $43 \%$ & 8 & $11 \%$ & 25 & $36 \%$ & 70 \\
\hline High tourism & 6 & $8 \%$ & 11 & $15 \%$ & 16 & $\underline{23 \%}$ & 38 & $\underline{54 \%}$ & 71 \\
\hline TOTAL & 36 & $13 \%$ & 105 & $37 \%$ & 38 & $13 \%$ & 103 & $37 \%$ & 282 \\
\hline Local labour system class & DMUs & $\%$ & DMUs & $\%$ & DMUs & $\%$ & DMUs & $\%$ & TOTAL \\
\hline Systems without specialization & 4 & $12 \%$ & 8 & $24 \%$ & 3 & $9 \%$ & 18 & $\underline{55 \%}$ & 33 \\
\hline Urban systems & 3 & $7 \%$ & 22 & $\underline{51 \%}$ & 4 & $9 \%$ & 14 & $33 \%$ & 43 \\
\hline $\begin{array}{l}\text { Tourism and agricultural } \\
\text { vocation systems }\end{array}$ & 5 & $12 \%$ & 9 & $21 \%$ & 9 & $\underline{21 \%}$ & 20 & $47 \%$ & 43 \\
\hline $\begin{array}{l}\text { Manufacturing systems in the } \\
\text { textile, leather and clothing }\end{array}$ & 12 & $\underline{16 \%}$ & 37 & $50 \%$ & 7 & $9 \%$ & 18 & $24 \%$ & 74 \\
\hline $\begin{array}{l}\text { Other manufacturing systems } \\
\text { made in Italy }\end{array}$ & 5 & $13 \%$ & 18 & $45 \%$ & 5 & $13 \%$ & 12 & $30 \%$ & 40 \\
\hline Heavy manufacturing systems & 7 & $14 \%$ & 11 & $22 \%$ & 10 & $20 \%$ & 21 & $43 \%$ & 49 \\
\hline TOTAL & 36 & $13 \%$ & 105 & $37 \%$ & 38 & $13 \%$ & 103 & $37 \%$ & 282 \\
\hline
\end{tabular}




\subsection{Efficiency explanatory variables: Tobit regression}

To summarize the evidence of the Sections 4.2 and 4.3 and in compliance with some of the existing literature (e.g. in Refs. [8, 15, 30, 68]), a Tobit re-

10.000 inhabitants, "Dim3" for municipalities from 10.000 to 20.000 inhabitants "Dim4" for municipalities from 20.000 to 60.000 inhabitants and "Dim5" for mu- 
nicipalities over 60.000 inhabitants. Regarding geo-demographic aspects, as in [8, 38, 42, 47, 50, the "density" of the municipality and the variable "mountain", equal to 1 for mountain municipalities according to the Italian legislation, are considered. According to [10, 13, 28, 29, 61], the importance of tourism is taken into account through the variable "tourism", defined as the ratio between the average annual tourist presence and the total population. The variable "second mandate" is finally introduced to take into account the potential influence of political factors on efficiency scores. Data are collected from the municipal balance sheets, the statistical databases DEMO ISTAT and ISTAT, Tuscany Region survey and ANCI TOSCANA and they all refer to 2011.

The Tobit regression is run for both the bias-corrected 3 global efficiency scores, the DEA-like and the average one, considered as the dependent variable, and implemented by the software "Stata". Table 6 contains the Tobit results for both the bias-corrected global efficiency scores: if an explanatory variable has a positive sign, it positively affects the efficiency and if it has a negative sign, the opposite holds.

\footnotetext{
${ }^{3}$ The bias-corrected efficiency scores are computed using 1000 replicates in the first stage. Some of the current literature suggests further bias-corrections to get more robust results (see e.g. [66]). For the present analysis, several Robust CIs have been computed: as they have a strong correlation with the CI obtained with the bias-corrected efficiency scores, the CI adopted in the analysis is considered sufficiently robust. The computations have been performed by using the statistical software R [58, in particular the packages "Benchmarking" [16] and "Compind" [67. Results are available upon request. The authors are grateful to an anonymous referee for suggesting these additional robustness checks.
} 
Table 6: Tobit results.

\begin{tabular}{lll}
\hline VARIABLE & DEA-like & Average \\
\hline AUTONOMY & $0.12425^{* * *}$ & $0.12842^{* * *}$ \\
REVENUES & $-0.00006^{* * *}$ & $-0.00005^{* * *}$ \\
DIM2 & $0.06775^{* * *}$ & $0.04688^{* * *}$ \\
DIM3 & $0.13973^{* * *}$ & $0.10775^{* * *}$ \\
DIM4 & $0.11424^{* * *}$ & $0.09983^{* * *}$ \\
DIM5 & $0.17529^{* * *}$ & $0.12472^{* * *}$ \\
DENSITY & 0.00004 & 0.00002 \\
MOUNTAIN & $-0.05683^{* * *}$ & $-0.04220^{* * *}$ \\
TOURISM & $-0.35370^{* * *}$ & $-0.31774^{* * *}$ \\
SECOND MANDATE & $0.02884^{*}$ & $0.02066^{*}$ \\
CONSTANT & $0.54073^{* * *}$ & $0.35756^{* * *}$ \\
\hline * 5\% significance, ** $1 \%$ significance, $* * * 0.1 \%$ significance
\end{tabular}

The results are very similar for both the model specifications, statistically

560 significant and in line with the literature main findings. The economic and financial variables have the expected sign. In fact, the degree of accountability measured by the variable "autonomy" positively affects the efficiency score, while the budget constraints measured by the variable "revenues" have a negative impact on it. The effect of the municipal characteristics on the efficiency scores confirms the descriptive analysis of the two previous sections. As it can be seen from the coefficients of the dimensional dummy variables, when the municipal size increases, the efficiency score increases as well. So, consistently with the in-depth analysis stemming from both the efficiency composite indicators adoption, the larger the municipalities the more efficient the expenditure management. Additionally, the results of the Wald tests performed by "Stata" show that the hypothesis of no differences between Dim2, Dim3, Dim4 and Dim5 is strongly rejected. The variable "density" shows a positive, though not statistically significant, impact on the efficiency index, as outcome in the majority of the studies. The negative impact of the variable "mountain" could be linked to the demographical aspects, as the mountain municipalities tend to be of a smaller size. Furthermore, the coefficient of the variable "tourism" confirms 
what shown in the descriptive analysis of the previous sections: municipalities with high level of tourism tend to be less efficient. Finally, the political variable "second mandate" has a positive coefficient: the incumbent politicians, in an effort to signal their competence to the voters so as to increase their chances to be reelected, tend to enlarge spending (inefficiently) when they are close to new elections [60. Administrations at the second mandate don't have the possibility to be elected again and therefore the positive effect on the spending efficiency is in line with the economic theory (see also [15]).

\section{Conclusions}

In this paper, the efficiency of Tuscan municipal expenditure is under scrutiny by means of Data Envelopment Analysis. The data referred to the municipal expenditure are taken from the available municipal balance sheets and the following functions are considered, given their importance on the total current expenditure: "General administration", "Educational services", "Social services", "Road maintenance and local mobility" and "Local police".

For the function by function analysis, a separate DEA model is run for each "fundamental" municipal area. For the overall analysis, addressing some methodological issues to compute the global efficiency score, the use of a DEAlike composite indicator is introduced, for the first time in this strand of literature. Moreover, a further composite indicator is proposed following another approach, strictly related to the municipal expenditure compositions. In this latter case, the efficiency score of each function enters in the global indicator with the same proportion that the given function has with respect to the total expenditure. Although the two composite indicators are derived following two very different approaches, the conclusions are basically the same. The first approach is closer to the principle of the DEA; the second one is more operative and it could suggest some normative indication to the policy-makers in terms of the expenditure distribution. In this light, the composite indicator obtained 
Tuscan mean weight; there are possible suggestions as room for improvement for the inefficient municipalities: in some cases, just a change in the composition of the expenditure could bring to an increase of the composite indicator efficiency score.

The results obtained through a DEA analysis and validated by the Tobit regression appear consistent and could be a starting point for the reallocation of the inefficient municipalities expenditure. In particular, some evidences about the long debated issue of the municipal size come out. In fact, according to this analysis, the municipal size really affects the efficiency of the public expenditure: the bigger is a municipality, the greater is its level of public spending efficiency, so that the regional measures to reduce the present fragmentation of the Tuscan territory seem to be in line with this evidence.

The performed analysis offers further insights from both a methodological point of view and an empirical one. Some of them are driven by the limitations of the analysis itself. It is well-know that a complete efficiency evaluation of the local government activities should also include the quality of the services and the citizens' satisfaction. As the present paper considers only quantitative data, a further stream of research could be the definition of suitable variables embedding both these qualitative aspects. Moreover the way of combining qualitative and 625 quantitative elements is still an open issue that should be investigated. The aggregation of these kinds of different data might suggest the necessity of the construction of other new composite indicators. With this regard, there exists a growing interest in the current scientific debate on the definition and the use of new composite indicators. Furthermore, the present study considers data referred just to one year. However, monitoring the changes on how public resources are spent over a larger period of time can represent a key point in the municipal spending efficiency analysis. For this reason, longitudinal data could be used to perform an intertemporal efficiency analysis by means of DEA window approaches. 


\section{Acknowledgements}

The authors would like to thank the two anonymous referees of the present paper for valuable criticism and suggestions.

The authors are also very grateful to the IRPET researchers for their support, helpful suggestions and productive comments.

Laura Carosi gratefully acknowledges financial support from the University of Pisa (PRA 2016 Project).

\section{References}

[1] Afonso, A., Schuknecht, L., Tanzi, V., (2005), "Public Sector Efficiency: An International Comparison", Public Choice, 123 (3-4), pp. 321-347.

[2] Afonso, A., Fernandes, S., (2006), "Measuring local government spending efficiency: evidence for the Lisbon region", Regional Studies, 40 (1), pp. $39-53$.

[3] Afonso, A., Fernandes, S., (2008), "Assessing and explaining the relative efficiency of local government", Journal of Socio-Economics, 37 (5), pp. 1946-1979.

[4] Afonso, A., Venâncio, A., (2016), "The relevance of commuting zones for regional spending efficiency", Applied Economics, 48(10), pp. 865-877.

[5] Agasisti, T., Dal Bianco, A., Griffini, M., (2016), "The public sector fiscal efficiency in Italy: the case of Lombardy municipalities in the provision of the essential public services", Economia Pubblica, 1, pp. 59-84.

[6] Agasisti, T., Wolszczak-Derlacz, J.,(2015), "Exploring efficiency differentials between Italian and Polish universities, 2001-11", Science and Public Policy.

[7] Aigner, D. J., Lovell, C. A. K., Schmidt, P., (1977), "Formulation and estimation of stochastic frontier production function models", Journal of Econometrics, 6 (1), pp. 21-37. 
[8] Athanassopoulos, A. D., Triantis, K., (1998), "Assessing aggregate cost efficiency and the policy implications for Greek local authorities", INFOR: Information Systems and Operational Research, 36 (3), pp. 66-84.

[9] Balaguer-Coll, M. T., Prior, D., Tortosa-Ausina, E., (2007), "On the determinants of local government performance: a two-stage nonparametric approach", European Economic Review, 51 (2), pp. 425-451.

[10] Balaguer-Coll, M. T., Prior, D., Tortosa-Ausina, E., (2013), "Output complexity, environmental conditions, and the efficiency of municipalities", Journal of Productivity Analysis, 39 (3), pp. 303-324.

[11] Banker, R. D., Chang H., (2006), "The super-efficiency procedure for outlier identification, not for ranking efficient units." European Journal of Operational Research 175 (2), pp. 1311-1320.

[12] Banker, R. D., Charnes, A., Cooper, W. W., (1984), "Models for the estimation of technical and scale inefficiencies in Data Envelopment Analysis", Management Science, 30 (9), pp. 1078-1092.

[13] Benito, B., Bastida, F., Garca, J. A., (2010), "The determinants of efficiency in municipal governments", Applied Economics, 42 (04), pp. 515528.

[14] Bernini, C., Guizzardi, A., Angelini, G., (2013), "DEA-like model and common weights approach for the construction of a subjective community well-being indicator", Social indicators research, 114 (2), pp. 405-424.

[15] Boetti, L., Piacenza, M., Turati, G., (2012), "Decentralization and local government's performance: how does fiscal autonomy affect spending efficiency?", FinanzArchiv: Public Finance Analysis 68 (3), pp. 269-302.

[16] Bogetoft, P., Otto, L., (2015), "Benchmarking with DEA and SFA", R package version 0.26 . 
[17] Bollino, C. A., Di Vaio, G., Polinori, P., (2012), "Spillover ed eterogeneità spaziali nei livelli di efficienza delle amministrazioni locali: un'applicazione ai comuni dell'Emilia-Romagna", Rivista di economia e statistica del territorio.

[18] Bönisch, P., Haug, P., Illy, A., Schreier, L., (2011), "Municipality size and efficiency of local public services: Does size matter?", IWHDiskussionpapiere, n.2011, 18.

[19] Borge, L. E., Falch, T., Tovmo, P., (2008), "Public sector efficiency: the roles of political and budgetary institutions, fiscal capacity, and democratic participation." Public Choice, 136 (3-4), pp. 475-495.

[20] Bowlin, W., (1998), "Measuring performance: An introduction to data envelopment analysis (DEA)", Journal of Cost Analysis, Fall 1998, pp. 3-27.

[21] Charnes, A., Cooper, W., Rhodes, E., (1978) "Measuring the efficiency of decision making units", European Journal of Operations Research, 2 (6), pp. 429-444.

[22] Cherchye, L., Moesen, W., Rogge, N., Van Puyenbroeck, T., (2007), "An introduction to 'benefit of the doubt' composite indicators", Social Indicators Research, 82 (1), pp. 111-145.

[23] Coelli, T., (1996), "A Guide to DEAP Version 2.1: A Data Envelopment Analysis (Computer) Program", CEPA Working Paper 96/08, Departments of Econometrics, University of New England, Armidale, Australia.

[24] Cook, W. D., Tone, K., Zhu, J., (2014). "Data envelopment analysis: Prior to choosing a model", Omega, 44, pp. 14.

[25] Cooper, W. W., Li, S., Seiford, L. M., Zhu, J., (2011), "Sensitivity analysis in DEA". In Cooper, W. W., Seiford, L. M., Zhu, J. (Eds.) "Handbook on data envelopment analysis", pp. 41-70, Springer US. 
[26] Cotte Poveda, A. (2012), "Estimating effectiveness of the control of violence and socioeconomic development in Colombia: an application of dynamic data envelopment analysis and data panel approach", Social indicators research, 105 (3), pp. 343-366.

[27] Cotte Poveda, A. (2014), "Corruption, Economic Development and Insecurity in Colombia: Evidence from Data Envelopment Analysis (DEA) and Dynamic Panel Data Model (DPDM)". In Osman, I., Latef, A., Emrouznejad, A., "Handbook of Research on Strategic Performance Management and Measurement Using Data Envelopment Analysis". IGI Global: International Publisher of Science and Technology.

[28] Cuadrado-Ballesteros, B., Garca-Snchez, I. M., Prado-Lorenzo, J. M., (2013), "Effect of modes of public services delivery on the efficiency of local governments: A two-stage approach", Utilities Policy, 26, pp. 23-35.

[29] Da Cruz, N. F., Marques, R. C., (2014), "Revisiting the determinants of local government performance", Omega, 44, pp. 91-103.

[30] De Borger, B., Kerstens, K., (1996), "Cost efficiency of Belgian local governments: a comparative analysis of FDH, DEA, and econometric approaches", Regional Science and Urban Economics, 26 (2), pp. 145-170.

[31] De Borger, B., Kerstens, K., (2000), "What is known about municipal efficiency? The Belgian case and beyond", in Blank, J.L.T. (ed.), Public provision and performance - contributions from efficiency and productivity measurement, Elsevier, Amsterdam et al., pp. 299-330.

[32] De Borger, B., Kerstens, K. Moesen, W., Vanneste, J., (1994), "Explaining Differences in Productive Efficiency: An Application to Belgian Municipalities", Public Choice, 80, pp. 339-358.

[33] Deller, S. C., Chicoine, D. L., Walzer, N., (1988), "Economies of Size and Scope in Rural Low-Volume Roads", Review of Economics and Statistics, 70 (3), pp. $459-465$. 
[34] Deprins, D. L., Simar, L., Tulkens, H., (1984), "Measuring labor-efficiency in post offices", in: Marchand, M., Pestieau, P., Tulkens, H., (eds) The performance of public enterprises: Concepts and measurement, North-Holland, Amsterdam, pp. 243-268.

[35] Despotis, D. K., (2002), "Improving the discriminating power of DEA: focus on globally efficient units", Journal of the Operational Research Society 53 (3), pp. 314-323.

[36] Despotis, D. K., (2005), "A reassessment of the human development index via data envelopment analysis", Journal of the Operational Research Society, 56 (8), pp. 969-980.

[37] Dollery, B., Wallis, JL., (2001), "The political economy of local government". Edward Elgar Publishing.

[38] Doumpos, M., Cohen, S., (2014), "Applying data envelopment analysis on accounting data to assess and optimize the efficiency of Greek local governments.", Omega, 46, pp. 74-85.

[39] Dunleavy, P., Margetts, H., Bastow, S., Tinkler, J., (2006), "New public management is dead-long live digital-era governance. Journal of public administration research and theory, 16,3, pp. 467-494.

[40] Dyson, R. G., Allen, R., Camanho, A. S., Podinovski, V. V., Sarrico, C.S., Shale, E. A., (2001), "Pitfalls and protocols in DEA", European Journal of Operational Research, 132, pp. 245-59.

[41] Farrell, M., (1957), "The measurement of productive efficiency", Journal of the Royal Statistical Society Series A (General) 120, pp. 253-281.

[42] Geys, B., Heinemann, F., Kalb, A., (2010), "Voter involvement, fiscal autonomy and public sector efficiency: evidence from German municipalities", European Journal of Political Economy, 26 (2), pp. 265-278. 
[43] Geys, B., Moesen, W., (2009), "Measuring local government technical (in) efficiency: An application and comparison of FDH, DEA, and econometric approaches", Public Performance \& Management Review, 32 (4), pp. 499513.

[44] Hayes, K., Chang, S., (1990), "The Relative Efficiency of City Manager and Mayor-Council Forms of Government", Southern Economic Journal, 57 (1), pp. 167-77.

[45] Hood, C., (1991), "A public management for all seasons?", Public Administration, 69, pp. 3-19.

[46] Iommi, S., (2012), "Numerosità e dimensione degli enti locali ed offerta dei servizi pubblici". In IRPET, "Il governo locale in Toscana. Identikit 2011", Studi per il Consiglio n. 8.

[47] Kalb, A., Geys, B., Heinemann, F., (2012), "Value for Money? German Local Government Efficiency in a Comparative Perspective", Applied Economics, 44 (2), pp. 201-218.

[48] Kornai, J., Maskin, E., Roland, G., (2003), "Understanding the Soft Budget Constraint", Journal of Economic Literature 41, pp. 1095-1136.

[49] Lo Storto, C., (2013), "Evaluating technical efficiency of Italian major municipalities: a Data Envelopment Analysis model", Procedia Social and Behavioral Sciences, 81, pp. 346-350.

[50] Lo Storto, C., (2016), "The trade-off between cost efficiency and public service quality: A non-parametric frontier analysis of Italian major municipalities." Cities, 51, pp. 52-63.

[51] Loikkanen, H. A., Susiluoto, I., (2005), "Cost efficiency of Finnish municipalities in basic service provision 1994-2002", Urban Public Economics Review, 4, pp. 39-64. 
[52] Nakazawa, K., (2013), "Cost Inefficiency of Municipalities after Amalgamation", Procedia Economics and Finance, 5, pp. 581-588.

[53] Nijkamp, P., Suzuki, S., (2009), "A generalized goals-achievement model in data envelopment analysis: an application to efficiency improvement in local government finance in Japan", Spatial Economic Analysis, 4 (3), pp. 249-274.

[54] OECD, (1998), "Public Management Reform and Economic and Social Development", PUMA, (Paris: OECD).

[55] Osborne, S.P., (2006), "The New Public Governance?" , Public Management Review, 8, 3, pp. 377-387.

[56] Owen, E. H., (2003), "Public management and administration", Third edition, Palgrave Macmillan.

[57] Prieto, A. M., Zofío, J. L., (2001), "Evaluating effectiveness in public provision of infrastructure and equipment: the case of Spanish municipalities", Journal of Productivity Analysis, 15 (1), pp. 41-58.

[58] R Core Team, (2015), "R: A language and environment for statistical computing".

[59] Reingewertz, Y., (2012), "Do municipal amalgamations work? Evidence from municipalities in Israel", Journal of Urban Economics, 72 (2), pp. 240-251.

[60] Rogoff, K., Sibert, A., (1988), "Elections and macroeconomic policy cycles", The review of economic studies, 55 (1), pp. 1-16.

[61] Sampaio de Sousa, M., Stosic, B., (2005), "Technical efficiency of the Brazilian municipalities: Correcting nonparametric frontier measurements for outliers", Journal of Productivity Analysis, 24, pp. 157-181. 
[67] Vidoli, F., Fusco, E., Mazziotta, C., (2015) "Non-compensability in composite indicators: a robust directional frontier method", Social Indicators Research, 122 (3), pp. 635-652.

[68] Worthington, A. C., (2000), "Cost efficiency in Australian local government: a comparative analysis of mathematical programming and econometric approaches", Financial Accountability \& Management, 16 (3), pp. $201-223$.

[69] Worthington, A. C., Dollery, B., (2000), "Efficiency measurement in the local public sector: Econometric and mathematical programming fron-

[62] Simar, L., Wilson, P. W., (2000), "A general methodology for bootstrapping in non-parametric frontier models", Journal of Applied Statistics, 27, pp. $779-802$.

[63] Simar, L., Wilson, P. W., (2007), "Estimation and inference in two-stage, semi-parametric models of production processes", Journal of Econometrics,

[64] Št́astná, L., Gregor, M., (2015), "Public sector efficiency in transition and beyond: evidence from Czech local governments", Applied Economics, 47 (7), pp. 680-699.

[65] Vanden Eeckhaut, P., Tulkens, H., Jamar, M.-A., (1993), "Cost-efficiency in Belgian municipalities". In Fried, H., Lovell, C., Schmidt, S. (Eds.), "The measurement of productive efficiency: Techniques and applications". New York: Oxford University Press.

[66] Vidoli, F., Mazziotta, C., (2013), "Robust weighted composite indicators by means of frontier methods with an application to European infrastructure endowment", Italian journal of applied statistics, 23 (2), pp. 259-282. tier techniques", School of Economics and Finance Discussion Papers and Working Papers Series 078, School of Economics and Finance, Queensland University of Technology. 